\title{
Psoriasis Epidemiology
}

\section{Moussa Diallo*}

Department of Dermatology, Aristide LeDantec Teaching Hospital, University of Dakar, BP 6821 Dakar-Etoile, Senegal

\section{Keywords: Psoriasis; Epidemiology; Prevalence}

Psoriasis is a chronic lifelong inflammatory dermatosis related to an anomaly of the proliferation and the differentiation of epidermal cells. Its first description dates back to 1808 by the British Robert William in his treatise of skin diseases. This affection concerns $1-3 \%$ of the world population, irrespective of gender. It is associated with high degree of morbidity and poor quality of life, and thus leads to a major impact on health care systems and on the society in general.

While the precise cause of the disease is still imperfectly known, there have been major advances in understanding its aetiopathogenesis, thus resulting in a remarkable increase of more targeted therapeutic resources such as biotherapies. Nevertheless, there are still many questions which remain unanswered and suspected associations between psoriasis and specific ethnic groups deserve to be studied, since they may lead to a better knowledge of genetic and/or environmental factors that could be involved in the aetiopathogenesis of this disease.

Psoriasis is prevalent worldwide but its frequency varies widely with "race" and geographical distribution. It is, according to most epidemiological data, respectively less frequent among the phototype VI (black population), followed by the intermediate phototypes (Asian) and finally within the phototype I and II (Caucasian population which is most concerned). Because of such observations, an inverse relationship has been postulated between the frequency of psoriasis and the degree of skin pigmentation. Its prevalence estimated around 3.5\% in Europe and the United States remains higher than those reported in Asian, native Indian and black population of African descent [1,2]. Population-based surveys from China and Japan have given a similar low prevalence ranging respectively from 0.05 to $1.23 \%$ and 0.29 to 1.18 $\%$. The same rates were found in India (0.5\%-2.3\%) [1-3].

Furthermore, there is considerable variability of the disease's prevalence between different populations of a comparable ethnic background or geographical location. A declarative survey from the USA has found $1.3 \%$ prevalence in African-Americans compared to 2.5 $\%$ in "Caucasians" [4]. In South Africa, the respective figures in Blacks (Bantu population) and Whites have been evaluated to be $1.5 \%$ vs. $4 \%$ [3]. In South America, it seems more frequent in persons of Indian descent than in those of African descent [5].

Interestingly, clinic and population surveys (where available), have shown great variability between different Sub-Saharan African populations. These suggest that West African countries like Nigeria, Ghana, Mali, Senegal, Angola etc, have a lower prevalence of psoriasis $(0.05 \%$ to $1 \%)$ than the eastern countries like Kenya, Uganda, Tanzania (3\%) [6]. If confirmed, this could explain why French and American Black populations, mainly originating from the West coasts of Africa, may have less psoriasis than other populations [4]. Finally, psoriasis has been found to be virtually absent in large-scale surveys of certain populations such as Eskimos or Australian Aborigines [1].

Psoriatic arthropathy also seems higher in white populations ( $11 \%$ in USA) than in Asian ( $1 \%$ in Japan) or African persons, where the prevalence of HLA-B27 haplotype is low (3-6 \% in certain African countries) $[1,7,8]$. It is entirely absent in natives of the Andean region of South America [1].

What could explain these variations? So far, there is no definite explanation for the variations in frequency of psoriasis with respect to "races" and regions. After accounting for study design, it is likely that some of the differences in the prevalence of psoriasis are due to differences in the genetic and environmental factors influencing susceptibility.

Genetic factors are probably involved as demonstrated by the family character of the disease. Therefore, heterogeneity of disease susceptibility has been suggested since different susceptibility loci for psoriasis have been identified in different groups of populations [9]. By far, the PSORS1 locus within the Major Histocompatibility Complex region on chromosome $6 \mathrm{p} 21$ provides the strongest link with psoriasis. This region codes for a number of genes important in the immune response, including HLA-Cw6, which is the haplotype bearing the most important risk factor in white populations. However, the distribution of HLA-Cw6 cannot explain the difference in prevalence among the various ethnic groups. Paradoxically, the highest prevalence of this allele has been reported in blacks (15.09\%) compared to Caucasoids (9.62\%) and Australian Aboriginals (9.05\%).

Therefore, besides a possible existence of genetic factors that promote resistance to psoriasis in certain groups of population, environmental influences (such as weather, cultural habits, socioeconomic factors, streptococcal/HIV infection, stress events, drugs) have been suspected to account for these observed differences and warrants further consideration. The protective role of sunlight has been particularly advocated to explain the low frequency of psoriasis in certain African countries; however, this cannot explain the difference between Black and non-Black Americans. Dietary habits (a nutrition poor in polyunsaturated fatty acids and rich in linoleic acid which is precursor of prostaglandin E2: a suppressor of cell-mediated immunity) are also evoked. It is believed that the high content of polyunsaturated fats in the diet and low plasma levels of arachidonic acid contribute to the reduced prevalence of inflammatory diseases such as psoriasis. An emphasis on the cardiovascular risk factors associated with psoriasis, including obesity and dyslipidemia, as well as tobacco and alcohol consumption has also been raised in recent literature from Western countries.

Finally, the heterogeneity of the epidemiology of psoriasis should prompt us to no longer consider this disease only as the result of a linear series of causes and effects but as an interactive multi-factorial disease. It is hoped that this perspective will help us better understand its pathogenesis.

*Corresponding author: Dr. Moussa Diallo, Department of Dermatology, Aristide LeDantec Teaching Hospital, University of Dakar, BP 6821 Dakar-Etoile, Senegal, E-mail: moussante@hotmail.com

Received March 30, 2012; Accepted April 12, 2012; Published April 18, 2012

Citation: Diallo M (2012) Psoriasis Epidemiology. J Clinic Case Reports 2:e116. doi:10.4172/2165-7920.1000e116

Copyright: @ 2012 Diallo M. This is an open-access article distributed under the terms of the Creative Commons Attribution License, which permits unrestricted use, distribution, and reproduction in any medium, provided the original author and source are credited. 


\section{References}

1. Chandran V, Raychaudhuri SP (2010) Geoepidemiology and environmental factors of psoriasis and psoriatic arthritis. J Autoimmun 34: J314-321.

2. Gudjonsson JE, Elder JT (2007) Psoriasis: epidemiology. Clin Dermatol 25: 535-546.

3. Farber EM, Nall L (1998) Epidemiology: natural history and genetics. In Roenigk Jr HH, Maibach HI, editors. Psoriasis. New York: Dekker 107-157.

4. Gelfand JM, Stern RS, Nijsten T, Feldman SR, Thomas J, et al. (2005) The prevalence of psoriasis in African Americans: results from a population-based study. J Am Acad Dermatol 52: 23-26.

5. Suite $M$ (2006) The epidemiology of psoriasis in a dermatology clinic in a general hospital in Port-of-Spain, Trinidad and Tobago, West Indies. West Indian Med J 55: 399-402.

6. Leder RO, Farber EM (1997) The variable incidence of psoriasis in subSaharan Africa. Int J Dermatol 36: 911-919.

7. Yang Q, Qu L, Tian H, Hu Y, Peng J, et al. (2011) Prevalence and characteristics of psoriatic arthritis in Chinese patients with psoriasis. J Eur Acad Dermato Venereol 25: 1409-1414.

8. Mijiyawa M, Oniankitan O, Khan MA (2000) Spondyloarthropathies in subSaharan Africa. Curr Opin Rheumatol 12: 281-286.

9. Sun LD, Cheng H, Wang ZX, Zhang AP, Wang PG, et al. (2010) Association analyses identify six new psoriasis susceptibility loci in the Chinese population. Nature Genet 42: 1005-1009. 